\title{
STUDY OF GRAFT COPOLYMERIZATION OF ACRYLIC ACID ONTO NATA DE COCO AND ITS APPLICATION AS MICROFILTRATION MEMBRANE
}

\author{
Tita Puspitasari ${ }^{1}$, Cynthia Linaya Radiman ${ }^{2}$ \\ ${ }^{1}$ National Nuclear Energy Agency, Centre for the Application of Isotopes and Radiation Technology, \\ P.O. BOX 7010 JKSKL, Jakarta 12070 \\ ${ }^{2}$ Inorganic and Physical Chemistry, Faculty of Mathematics and Natural Sciences, \\ Institut Teknologi Bandung Jl. Ganesha No. 10, Bandung 40132
}

\begin{abstract}
STUDY OF GRAFT COPOLYMERIZATION OF ACRYLIC ACID ONTO NATA DE COCO AND ITS APPLICATION AS MICROFILTRATION MEMBRANE. Chemical and physical modifications of membrane can be carried out by radiation induced graft copolymerization. The aim of this research is to prepare graft copolymers of acrylic acid onto nata de coco (NDC-g-AAc) by radiation and to study the performance of grafted copolymer as microfiltration membrane. Using a total dose of $30 \mathrm{kGy}$, the highest degree of grafting obtained were $209 \%$ and $142 \%$ for $r$ (weight ratio of monomers to nata de coco) equal to 61.3 and 35.7 respectively. The increasing degree of grafting resulted in decreasing flux due to high hydrogen bonding between grafted acrylic groups and water. It was found that the degree of swelling of NDC-g-AAc membrane with $r=35.7$ was higher than that of $r=63.1$. The changes of chemical structure of membrane were characterized by FTIR spectroscopy which showed a new band at $1720 \mathrm{~cm}^{-1}$ attributed to the carbonyl group of acrylic acid.
\end{abstract}

Keywords: Graft copolymerization, nata de coco, microbial cellulose, acrylic acid, microfiltration membrane

\section{INTRODUCTION}

Cellulose is the most abundant biopolimer on earth and recognized as the major component of plant biomass. The most efficient celluloseproducing bacterium and widely used is acetobacter xylinum which produced nata de coco (NDC) when fermented in coconut water.

One of the most important features of microbial cellulose is its chemical purity, which distinguishes this cellulose from that of plant, usually associated with hemicelluloses and lignin [1].

Because of its interesting properties, NDC has found in wider application in paper, textile, food industries, and as biomaterial in cosmetics and medicine [2-4]. Cellulose and its derivatives can also be used as microfiltration, ultrafiltration and reverse osmosis membrane.

Nowdays, membrane filtration is widely used in many application, such as production of drinking water, yeast filtration and fruit juice concentrating in food industries, and bacteria filtration in waste treatment [5].

Chemical and physical modifications of membrane can be carried out by radiation induced graft copolymerization which offers a versatile way to impart desirable properties into a polymer without much affecting its original characteristics. Moreover, graft distribution may be achieved throughout the 
matrix bacause of the radiation activation of film across its thickness. Radiation induced graft copolymerization of acrylic acic onto polymer and its application as a membrane have been done widely [6,7]. Therefore, the aim of this research is to study the effect of graft copolymerization of acrilyc acid onto nata de coco (NDC) and its application as microfiltration membrane.

\section{MATERIALS AND METHOD}

\section{Materials}

Acetobacter xylinum was obtained from a home industry in Cianjur, while coconut water and sugar were both obtained from traditional markets. Other chemicals such as glacial acetic acid, ammonium sulfate, acrylic acid, phenol and sulfuric acid were supplied by E. Merck.

\section{Preparation of nata-de-coco (NDC) film}

Five liters of filtered coconut water were boiled, then added with $10 \%$ $(\mathrm{w} / \mathrm{v})$ sugar, and $0.5 \%(\mathrm{w} / \mathrm{v})$ ammonium sulfate. Furthermore, glacial acetic acid solution was added to the mixture to maintain the $\mathrm{pH}$ equal to 3 . The hot solution then was distributed to the plastic tray. After cooling, then $10 \%$ $(\mathrm{w} / \mathrm{v})$ Acetobacter xylinum was incubated at $30^{\circ} \mathrm{C}$ for 6 days. NDC gels were harvested and washed with boiling water for 15 minutes to remove residual medium component, and treated with $1 \% \mathrm{NaOH}$ and $1 \% \mathrm{CH}_{3} \mathrm{COOH}$ solutions at room temperature and kept overnight, respectively. Furthermore, NDC gels was washed with running water. Afterthat, the NDC gels were put between two stainless steel plat of hot press equipment for 5 minutes as preheating, then pressed at $150 \mathrm{kgf} / \mathrm{cm}^{2}$ and $80^{\circ} \mathrm{C}$ for 5 minutes and finally dried at room temperature to get NDC film.

\section{Preparation of copolymer NDC-g-AAc membrane}

Nata de coco- $g$-acrylic acid (NDC- $g$-AAc) membranes were prepared by graft copolymerization of acrylic acid onto NDC film by preirradiation method. Gamma-irradiation was carried out on open air at a radiation dose rate of $7 \mathrm{kGy} / \mathrm{h}$ using ${ }^{60} \mathrm{Co}$ (IRKA-Centre for the Application of Isotopes and Radiation Technology, Jakarta, Indonesia). Furthermore, graft copolymerization was done on gamma-irradiated NDC films under nitrogen athmosphere in a glass tube containing acrylic acid solution of desired concentration. Water-methanol was used as a medium for the grafting reaction. The weight ratio of monomer to NDC was defined as $r$ and calculated according to the following equation: 


$$
\mathrm{r}=\frac{[\mathrm{C} \times \mathrm{V} \times \rho / 100]}{\mathrm{W}_{\text {membrane }}}
$$

where :

$\mathrm{C}=$ concentration of acrylic acid solution

$\mathrm{V}=$ volume of acrylic acid solution

$\rho=$ density of concentrated acrylic acid

$\mathrm{W}_{\text {membrane }}=$ weight of NDC membrane

The graft copolymerization reaction was carried out for 60 minutes at temperature of $60^{\circ} \mathrm{C}$, nitrogen gas was flushed 15 minutes before and during the process. The grafted film then washed with hot water for 24 hours to remove the residual monomer and homopolymer entrapped in the film, then the grafted film was dried in the oven at $60^{\circ} \mathrm{C}$ until a constant weight was obtained. The degree of grafting was gravimetrically determined as the percentage of weight increase of the NDC film using the following equation:

$\begin{aligned} & \text { Degree of } \\ & \text { grafting }(\%)\end{aligned}=\frac{\mathrm{W}_{\mathrm{g}}-\mathrm{W}_{\mathrm{o}}}{\mathrm{W}_{\mathrm{o}}} \times 100 \%$

where $\mathrm{W}_{\mathrm{g}}$ and $\mathrm{W}_{\mathrm{o}}$ are the the weights of grafted and original NDC films, repectively.

\section{Determination of degree of swelling}

Degree of swelling measurements were carried out by immersing clean and dried membrane samples in deionized water until swelling equillibrium is reached. Original and grafted NDC film was cut into pieces $\left(1 \times 2 \mathrm{~cm}^{2}\right)$ and weighed. After immersing, the excess of water adhering to the surface was quickly wiped by absorbent paper and then membrane samples were weighed. The degree of sweeling was calculated according to the following equation:

$$
\operatorname{DS}(\%)=\frac{\mathrm{W}_{\mathrm{w}}-\mathrm{W}_{\mathrm{d}}}{\mathrm{W}_{\mathrm{d}}} \times 100 \%
$$

Where, $\mathrm{W}_{\mathrm{w}}$ and $\mathrm{W}_{\mathrm{d}}$ are the weights of wet and dried membranes respectively.

\section{Membran permeability measurements}

Permeability and permselectivity of membranes were measured according to similar procedures described previously [8]. 


\section{FTIR measurements}

FTIR measurement of ungrafted and grafted NDC films were carried out with an FTIR spectrometer (Perkin Elmer Spektrum One) at ambient condition in the transmittance mode at wave number of $450-4000 \mathrm{~cm}^{-1}$.

\section{RESULTS AND DISCUSSION}

\section{NDC- $g$-AAc copolymerization}

The effect of the irradiation dose on degree of grafting of acrylic acid onto NDC is shown in Figure 1. The degree of grafting increases with increasing of total irradiation doses and value of $r$.

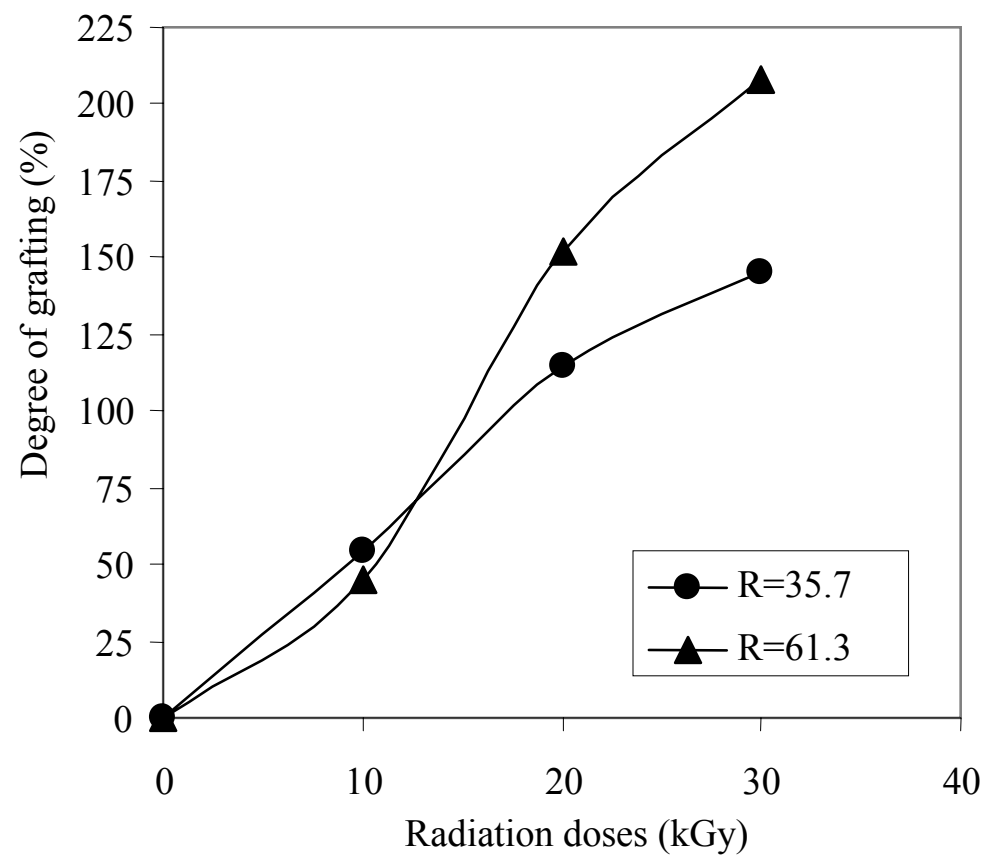

Figure 1. Effect of irradiation dose on degree of grafting.

Using a total dose of $30 \mathrm{kGy}$, the highest degree of grafting obtained were $209 \%$ and $142 \%$ for $\mathrm{r}$ (weight ratio of monomers to nata de coco) equal to 61.3 and 35.7 , respectively. It means that increasing irradiation dose gave higher degree of grafting due to higher amount of acrylic acid supplied for copolymerization reaction. Consequently, the increased amount of monomer led the acrylic acid to diffuse more into polymer matrix resulted in higher probability of collision between monomers and polymer radicals [9]. 


\section{Degree of swelling}

The effects of degree of grafting on the degree of swelling of NDC-gAAc copolymers is presented in Figure 2. The degree of swelling of NDC itself was $150 \%$ and it increases significantly with the increase of degree of grafting. This result showed that the resulting copolymer has higher hydrophilicity properties. The incorporation of more $-\mathrm{COOH}$ groups from acrylic acid to NDC is believed to occur with the increase of the degree of grafting and caused higher hydrogen bonding between grafted acrylic acid groups and water. It was also found that for the same degree of grafting, the NDC-g-AAc membrane with $r=35.7$ shows a degree of swelling remarkably higher than that of $r=63.1$.

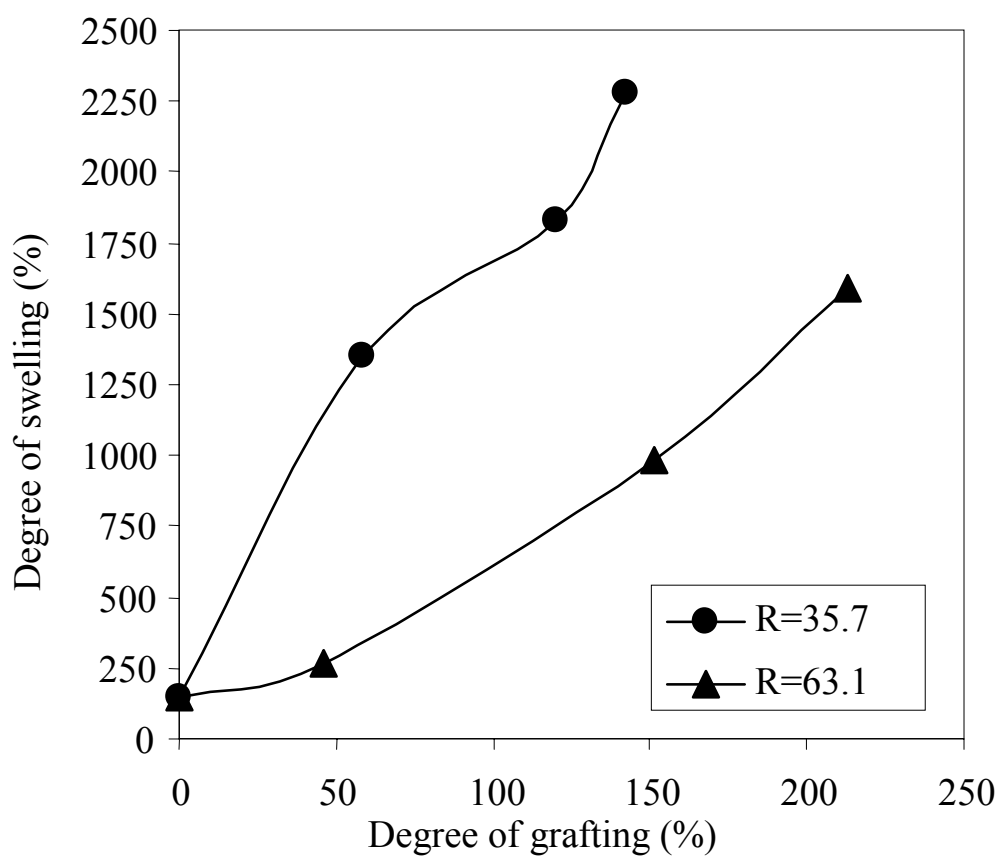

Figure 2. Effect of degree of grafting on degree of swelling.

\section{Membrane permeability}

The permeability of both NDC and NDC-g-AAc membrane are shown in Figure 3. It can be seen that the water flux decreases with the increase of degree of grafting. Comparing the hydrophilicity of the grafted and the original membrane, one can expect that grafted membranes should have higher water flux. In facts, the results show the opposite effect. It seems that the interaction between the membrane and water become tighter due to the presence of polar groups from acrylic substituents which build more 
hydrogen bonds. This membrane-water interaction tends to retain water in the membrane vicinity and hence, it takes more time for water to permeate through the membrane. It was also found that the flux of water was almost the same for degrees of grafting ranging between 80 and $100 \%$. It seems that the existing interaction between membrane and water in those membranes have already achieved their equillibrium state.

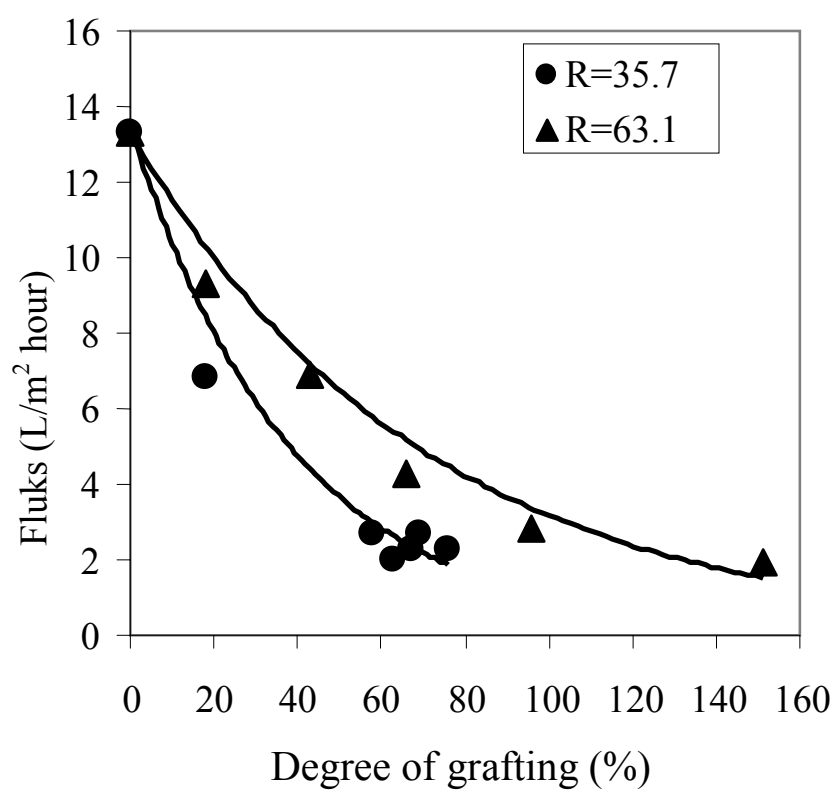

Figure 3. Effect of grafting on water flux.

\section{Membrane permselectivity}

The permselectivity of NDC and copolymer NDC-g-AAc membrane is shown in Figure 4. The result shows that rejection coefficient increases with the increase of degree of grafting. This phenomena is in line with the results of membrane permeability discussed previously. The increase of rejection coefficient with increasing degree of grafting indicates that the membranes become more dense. The change of membrane porosity retains the solute molecules to pass through membrane. So, radiation induced grafting onto NDC caused a modification of membrane characteristics, shown by the decreasing flux and increasing rejection coefficient. It can be seen from the figure that higher solute's molecular weight gave higher rejection coefficient. At the degree of grafting of 50\%, the rejection coefficient of dextran T-2000 attained more than $80 \%$. 


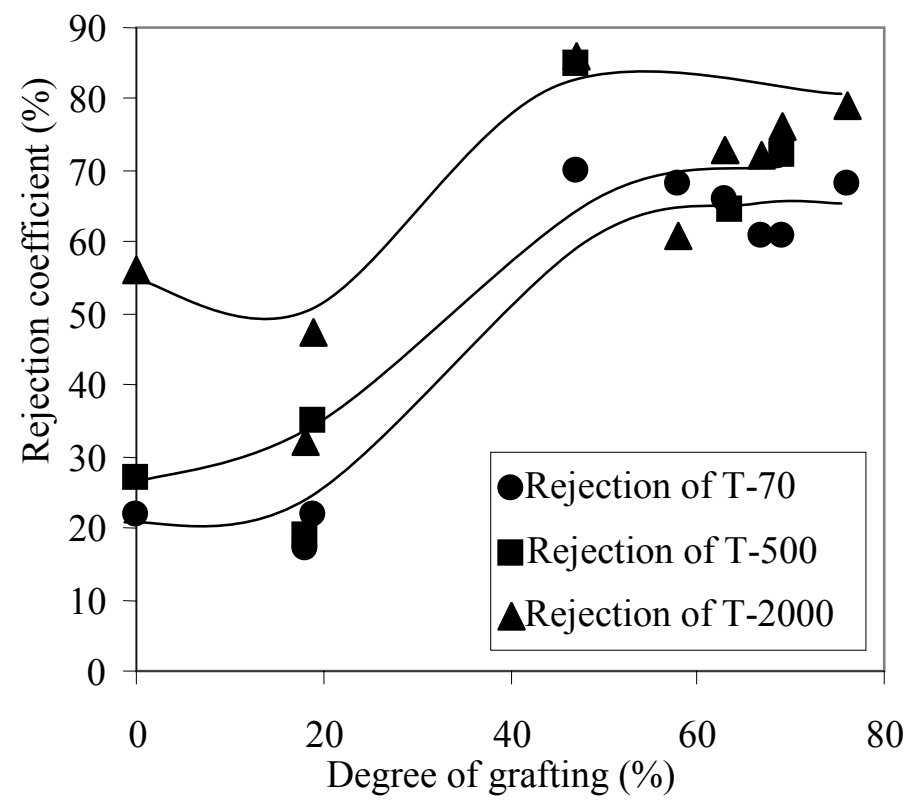

Figure 4. Effect of degree of grafting on rejection coefficient of dextran solution.

\section{FTIR measurement}

The FTIR spectra of ungrafted NDC and the NDC-g-AAc copolymer with the degree of grafting of $142 \%$ are shown in Figure 5 and 6 , respectively. The main difference between the spectra of ungrafted NDC and NDC-g-AAc is the peak at $1720 \mathrm{~cm}^{-1}$. This peak is assigned to the $\mathrm{C}=\mathrm{O}$ streching vibration of the acrilyc acid [10]. The spectra shows that the absorption bands associated with the grafted NDC increase in the degree of grafting. The proposed structure of grafted copolymer NDC-g-AAc is presented in Figure 7. 


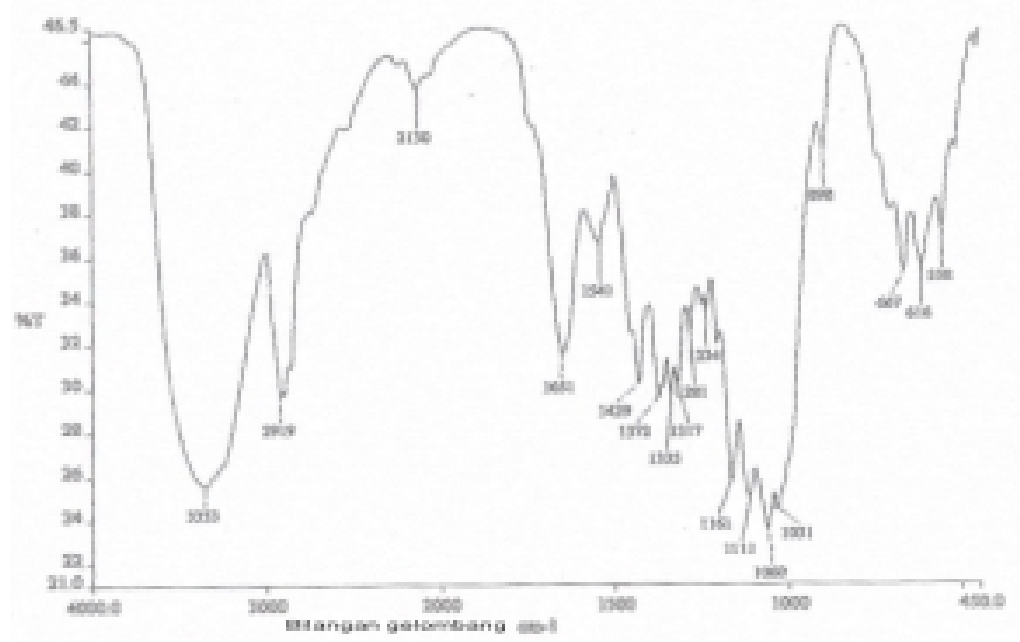

Figure 5. FTIR spectrum of ungrafted NDC membrane.

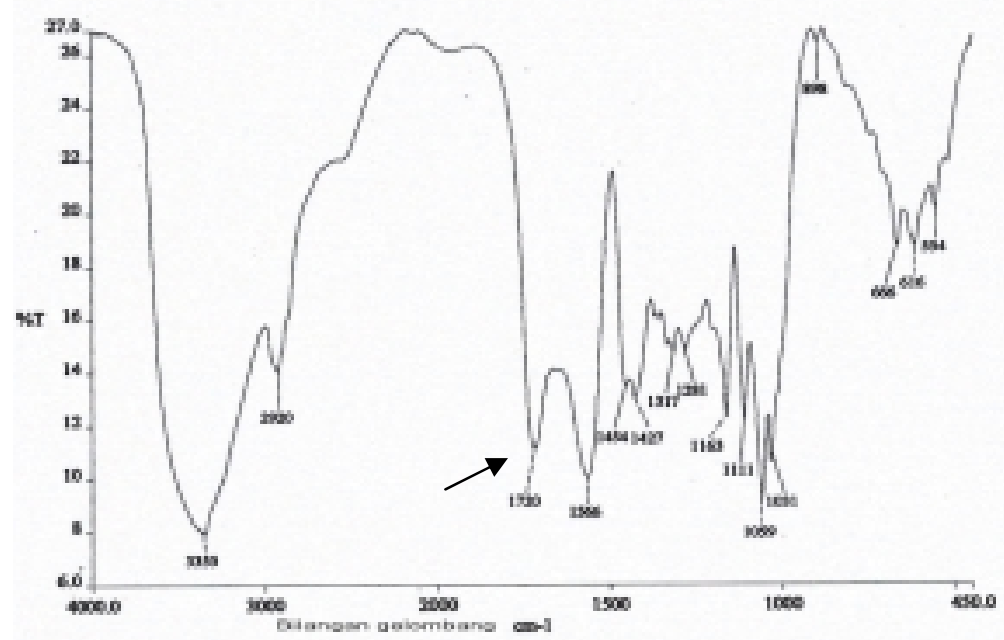

Figure 6. FTIR spectrum of NDC-g-AAc membrane (142\%). 


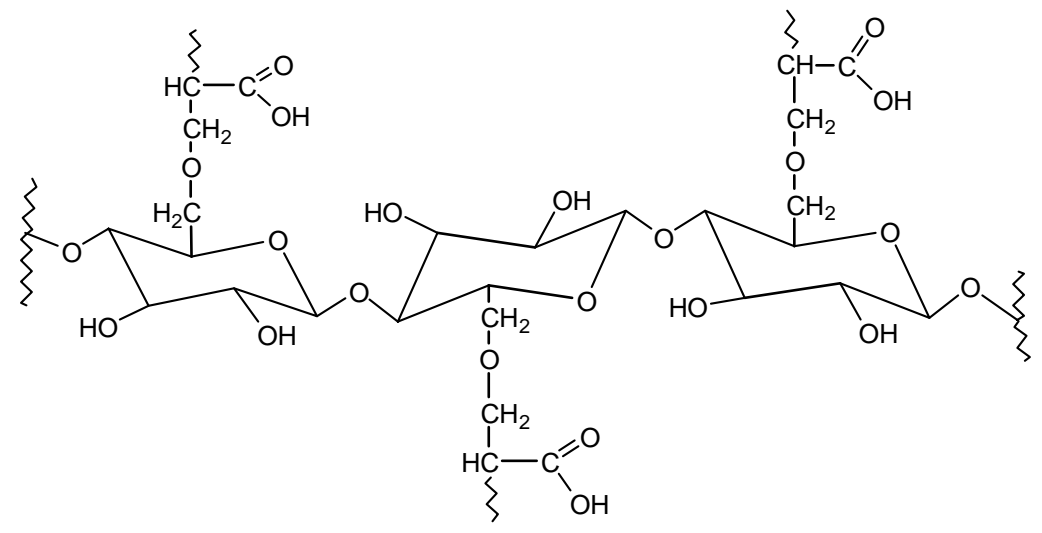

Figure 7. Structure of grafted copolymer NDC-g-AAc.

\section{CONCLUSION}

The highest degree of grafting obtained were $209 \%$ and $142 \%$ for $r$ (weight ratio of monomers to the nata de coco) equal to 61.3 and 35.7, respectively by using a total dose of $30 \mathrm{kGy}$. The performance of grafted copolymer as microfiltration membrane showed that the increasing of degree of grafting resulted in decreasing flux due to high hydrogen bonding between grafted acrylic groups and water. The degree of swelling of NDC-g-AAc membrane with $r=35.7$ was higher than that of $r=63.1$. The changes of chemical structure were characterized by FTIR spectroscopy which showed a new band at $1720 \mathrm{~cm}^{-1}$ attributed to the carbonyl group of acrylic acid.

\section{REFERENCES}

1. BROWN, R.M., JR., WILLISON, J.H.M., RICHARDSON, C.L., Cellulose biosynthesis in Acetobacter xylinum: 1. Visualization of the site of synthesis and direct measurement of the in vivo process. Proc. Nat. Acad. Sci. U.S.A. 73 (12) 4565-4569 (1976).

2. SHIBASHAKI, H., KUGA, S., ONABE, F., USUDA, M., Bacterial Cellulose Membran as Separation Medium, Journal of Applied Polymer Science, 50, 965-969 (1993).

3. NISHI, Y., URYU, M., YAMANAKA, S., WATANABE, K., KITAMURA, N., IGUCHI, M., The Structure and Mechanical Properties of Sheet Prepared from Bacterial Cellulose, Journal of Material Science, 24, 3141-4145 (1990). 
4. IGUCHI, M., YAMANAKA, S., BUDHIONO, A., Review Bacterial Cellulose, a masterpiece of Natural's Arts, Journal of Material Science, 35, 261-269 (2000).

5. MULDER, M., Basic Principles of membran Technology, Kluwer Academic Publishers (1996).

6. GUPTA, B., ANJUM, N., SEN, K., Development of Membran by Radiation Grafting of Acrilamide into Polyethilene Films: Properties and Metal Ion Separation, Journal of Applied Polymer Science, 85, 282-291 (2002).

7. NASEF, M. M., SAIDI, H., NOR, H. M., FOO, O. M., Cation Exchange Membranes by Radiation-Induced Graft Copolymerization of Styrene onto PFA Copolymer Films. II. Characterization of Sulfonated Graft Copolymer Membranes, Journal of Applied Polymer Science, 76, 1-11 (2000).

8. C.L. RADIMAN, H. SANGKANPARAN, V.S. PRAPTOWIDODO and OEI BAN LIANG. Desalination, 93, 273-286 (1993).

9. CHAPIRO, A., Radiation Chemistry of Polymeric System, John Wiley \& Sons, New York, (1962).

10. SILVERSTEIN, R.M., BASLER, G.C., MORRIL, T.C., Spectrometric Identification of Organic, 5th edition, John Wiley \& Sons, Toronto (1991). 